\title{
Index nominum antiquorum
}

Accio 204, 209

Acheronte 99, 210, 338

Aezio 6, 16, 130, 141 196, 207-208, 248

Anassimandro VII, 2, 7

Anassagora 2, 10, 67, 120, 141-143, 175

Antioco di Ascalona 19, 21, 130, 141, 162

Antistene di Rodi 22

Apollonio Rodio 189

Apuleio 114

Arato di Soli 9, 19-20, 97, 114, 123-124, 289-290, 301

Arcesilao XI, 21

Aristeo di Crotone 6

Aristotele VIII-X, XII, 2-3, 6-8, 11, 14, 1620, 33, 40-41, 43-45, 48, 60-61, 93, $119-124,128-130,136-137,140,161-$ 162, 207, 227-230, 245-247, 289, 301, 310-313, 316-322

Atlante 114

Augusto 22

Berosso 22

Boeto di Sidone $\quad$ XI, 19, 93, 124, 139

Callimaco 256

Callistene di Olinto 217

Calveno Tauro 9

Cariddi 252, 292-293

Carneade XI, 19, 21, 43, 54, 86, 158, 163, 181, 239, 248

Catilina 24

Catone il Censore 227

Catullo 189, 279, 288

Cesare 23

Cicerone XI, 5, 18-25, 55-56, 115, 122-125, 128, 132-133, 137-138, 141, 146, 151, $156,160,163,171$, , 242, 247-248, 250, 255, 269, 282, 290, 299, 306, 321, 336, 341

Cleante IX, 11, 56, 117, 120

Cleomede $\quad 48,60-61,121$

Columella 264, 277, 287-288

Cornuto X, 96

Crantore 9
Crisippo $\quad \mathrm{X}-\mathrm{XI}, 11,13,43,48,51-52,58-$ $59,80,129,139,141,158$

Critolao XIV, 17-19, 77-78, 86-90, 93-95, 161, 227, 245-247, 314, 322, 324, 328

Demetrio Falereo 113

Demetrio Lacone $\quad 25-26,157,163,186$, 248, 252, 255, 303, 309, 312

Democrito VII, 3-5, 10, 12-13, 75, 81-82, 89, 117, 231, 291

Dicearco 6, 18-19, 89

Diodoro Siculo XV, 191-195

Diogene di Enoanda XIV-XV, XXII, 16, 26, $132,137-138,143-144,152,156,158$, 163, 206, 236-237, 242, 248, 308, 326

Diogene di Seleucia 19

Dione Crisostomo IX-X

Dionisio di Alessandria 312-314

Eliadi 191, 193, 195

Empedocle VII, XIV, XVII, XXIII, 2-3, 7, 10, 27, 32, 54, 62, 67, 69, 80, 87, 109-112, $117,175,190,201,220,242,254,256$, 265, 289-302, 313, 316, 323, 328, 330, 338

Ennio 20, 112, 204, 276, 289, 302, 306, 331

Epicuro XIII-XIV, XVI, XXII, 3-4, 13-18, 25$28,30-34,38,40-42,45-47,50,67$, $69-70,74-78,80,83-85,87.89,93-$ $94,100-101,109,111,116-117,120-$ 122, 125-126, 130, 133, 136, 138, 141, 151, 156-158, 162-163, 165, 177-183, 202, 204-209, 211, 216, 219, 229-232, 236-237, 239, 242, 244-248, 250-253, 255, 259-260, 262-264, 266-269, 280, 289, 291-294, 297, 301-302, 304, $306-$ 315, 324-325, 327-331, 333-334, 336, 338-339, 341

Eraclito VIII-IX, 2, 328

Eratostene di Cirene 322

Ercole 109, 112

Eschilo 193-195

Esiodo 1, 2, 54, 68-69, 194, 273, 279, 289, 293-294, 300, 338 
Eudosso di Cnido 9, 116

Euripide $112-113,175,190,193-196,316$

Fedro (epicureo) 137

Ferecide di Siro 6

Fetonte $8,164,186,188-196,199,265$, 311, 320-321, 329

Filodemo di Gadara $\quad 26,129,132,137,157$, 171, 239, 256, 266, 284, 308-309, 316, 321

Filone Alessandrino IX, XI, XIV, XVI, 12, 1617, 21, 40, 54, 67, 77-78, 85-94, 113, 121, 141, 151, 159-160, 163-166, 178, 181-182, 231, 239-242, 247-250, 252, 288, 322

Filone di Larissa 21

Filopono 9, 21

Giganti XIV-XV, 8, 31, 100, 118-122, 128, 135, 172, 186-199, 211, 297, 301, 328, 334

Giove (Zeus) $\quad 20,69,102,111,117,191-$ 193, 196, 214, 289, 293-294

Ippaso di Metaponto VIII, 2

Lattanzio 22, 138, 179

Leucippo VII, 3-4, 81-82

Licofrone 23

Livio 281

Livio Andronico 112

Lucano 24

Luciano di Samosata 284

Lucilio XII, 284

Magna Mater (Cibele) 95-96, 283, 288, 336-337

Manilio 57-58, 65, 194

Marte 299-300, 323, 327

Memmio $\quad 23,39,117,135,314$

Metrodoro di Chio 74-75, 234, 312

Mitridate 22

Nausifane 4

Nemesio di Emesa $X$

Nicola di Damasco 322

Nigidio Figulo 24

Novio 284

Ocello Lucano $18,77,85$

Omero 1, 110, 276, 293, 309, 324

Orazio 174, 272-273, 277, 279, 293

Ovidio XXI, 189, 191, 193, 290, 332

Pacuvio 109, 118, 175, 204
Panezio XI-XIII, 19-21, 34, 67, 72, 124, $139,141,250$

Parmenide VII, 3, 6, 115, 117, 265, 313

Pitagora 6, 289, 313

Platone VII, IX, XI, XIII-XIV, 3, 5-11, 14, 33, 42, 45-46, 48-50, 60, 66, 76, 80, 90, $96,113,115-117,120,123-124,129-$ 130, 132, 136-144, 151, 160-163, 178, 182, 186, 190, 194-195, 198, 226, 236, 245-248, 269, 301, 313, 324-325, 327, 330

Plauto 274-277, 279-280, 283-285

Plinio il Vecchio 59, 62, 207

Plutarco IX, 43-45, 48-55, 60-62, 111, 293-294

Polistrato $155,157-163,225,323$

Posidonio XIII, 19, 34, 60, 115

Properzio 290

Pizia 118, 292, 297

Quintiliano 23, 309

Scrofa 288

Senarco di Seleucia 10, 17

Seneca XXI, 32, 55, 70, 97, 103, 141, 159, 163, 204, 216-217, 219, 232, 254, 256, 274-275, 308

Senocrate 9,60

Senofane VII, 7, 97, 151

Sofocle 61, 112-113, 318, 319

Sparti $86-88$

Speusippo 9

Strabone 132, 231, 322

Stratone di Lampsaco 17

Svetonio 22, 24

Taruzio Firmano 22

Teagene di Reggio 2

Teofrasto VIII, XV, 2, 16-18, 33, 40, 44, 88, 136-137, 164-165, 169-183, 189190, 194-196, 207-208, 228, 230-231, 236, 246-247, 315-316, 322-323

Terenzio 273, 277, 279

Tiberio Giulio Alessandro X, 159, 239-240, 322

Tifone $1,32,102,111,126,291,293-294$, 297-298, 301, 328, 338

Tucidide $\quad 238-239,299-300$

Varrone $18-23,25,103,130,162,189$, 250, 285-286, 288-289, 299, 304 
Varrone Atacino 189

Vegoia 22, 253, 288

Vettio 22

Virgilio XXII, 255, 274, 276, 280, 305

Vitruvio 114
Venere 291, 299, 323-324

Zenone di Cizio IX, 11, 41, 43, 45, 47, 51, $58,88,165$

Zenone di Sidone 137, 309

Zenone di Tarso XI 